\title{
Pola Kredit Usaha Mikro Kecil Menengah (UMKM) Kelompok Bank dan Fintech di Indonesia
}

\author{
Dipa Teruna ${ }^{1}$, Tedy Ardiansyah ${ }^{2 *}$ \\ ${ }^{1}$ Universitas Nasional, ${ }^{2}$ Universitas Indraprasta PGRI \\ email: *tedy.ardiansyah@unindra.ac.id
}

\begin{abstract}
The purpose of this study is to find models or patterns from bank and fintech groups for the progress of MSME (micro, small and medium enterprises) in assisting with funding and supervision related to finance. The research method is a qualitative research where the approach is carried out through a literature study, namely research that examines critically knowledge, ideas or findings and provides theoretical and methodological contributions to the object of study. The data used are secondary data in the form of interviews. The results of this study show that the map or model of each bank and fintech has formed policies that support each other, both banks and fintech. Banks must support MSME with appropriate and effective BCD (Bank Credit Distribution) policies for MSME actors or entrepreneurs and KB (Bank Policy) which must be flexible, friendly and controlled to MSME actors or entrepreneurs so that they do not experience total losses or go bankrupt. While Fintech has similarities in determining policies by informants, namely FP (Fintech Policies) and FC (Fintech challenges) where these 2 policies will trigger the success of MSME actors or entrepreneurs in carrying out entrepreneurial activities with fintech support.
\end{abstract}

Keywords: UMKM, Credit, Bank, Fintech

\begin{abstract}
Abstrak:Penelitian UMKM adalah bagian penting sebagai penggerak roda perekonomian di Indonesia, disamping tahan akan terpaan akan risiko kerugian, juga banyak mengurangi risiko kerugian. Tujuan dari penelitian ini adalah untuk mencari model atau pola dari kelompok bank dan fintech terhadap kemajuan UMKM dalam membantu mengenai pendanaan dan pengawasan yang menyangkut dengan keuangan. Metode penelitian adalah penelitian kualitatif dimana pendekatan yang dilakukan melalui studi literatur yaitu penelitian yang mengkaji secara kritis pengetahuan, gagasan atau temuan serta memberikan kontribusi teoritis dan metodologis terhadap objek kajian. Data yang digunakan data sekunder berupa data tidak langsung. Hasil penelitian ini menunjukan suatu reka cipta bahwa map atau model dari masing-masing baik bank dan fintech telah membentuk kebijakan yang mendukung satu sama lain baik itu bank dan fintech. Bank harus mendukung UMKM dengan kebijakan PKB (Penyaluran Kredit Bank) yang tepat dan berdaya guna bagi pelaku atau wirausaha UMKM dan KB (Kebijakan Bank) yang harus flexibel, ramah dan terkontrol terhadap pelaku atau wirausahawan UMKM sehingga tidak mengalami kerugian total alias bangkrut. Sedangkan Fintech mempunyai kesamaan dalam menentukan kebijakan oleh pihak informan yaitu KF (Kebijakan Fintech) dan TF (tantangan Fintech) yang mana 2 kebijakan ini akan memicu keberhasilan pelaku atau wirausahawan UMKM dalam melakukan kegiatan wirausaha dengan dukungan fintech.
\end{abstract}

Kata Kunci: UMKM, Kredit, Bank, Fintech

Copyright (c) 2021 The Authors. This is an open access article under the CC BY-SA 4.0 license (https://creativecommons.org/licenses/by-sa/4.0/) 


\section{PENDAHULUAN}

Bisnis kredit usaha mikro kecil dan menengah sangat menggiurkan apabila melirik jumlah UMKM yang diperkirakan sebanyak 59,2 juta peran koperasi dan usaha kecil menengah jumlah usaha mikro dan kecil 59,203,509 atau sekitar 95\% dari jumlah total UMKM sedangkan usaha menengah 59,263 perusahaan adapun yang tergolong sebagai usaha besar hanya 4,987 perusahaan menilik data itu jumlah usaha mikro dan kecil merupakan mayoritas di sektor usaha di Indonesia kehadiran UMKM diakui pemerintah dan swasta ikut menggerakkan roda perekonomian (Adibah, 2018; Budiarto, et al., 2018; Hasanah, N., \& Priantina, 2017; Kara, 2013; Rifa'i, 2010; Suci, 2017; Suryadi et al., 2017). Peran dalam potensi UMKM menurut kajian Bank Indonesia sangat menggiurkan untuk dilayani perbankan peluang kredit mikro sangat besar karena pelaku usaha di Indonesia itu 70\% adalah sektor informal dan 30\% nya sektor formal (Anggraeni, 2013; Sudaryanto, R., \& Wijayanti, 2013; Sudjinan, S., \& Juwari, 2018).

Bagaimana cara meningkatkan penyaluran kredit kecil dan mikro ini?, kajian ini Indonesia menunjukkan sekitar 70\% usaha mikro dan kecil di Indonesia tidak tertarik menambah modal lewat pembiayaan bank atau kredit usaha alasannya beragam mulai dari prosedur kredit yang rumit sulitnya mendapatkan persetujuan dari bank tidak semua produk kredit dari Bank menerima pengajuan kredit dari UMKM sehingga ketiadaan jaminan yang memadai (Budhi, 2018; Irwan, 2020; Nisa, 2016).

Dengan sejumlah negara lain penyerapan kredit untuk UMKM pun masih sangat kecil,(Kara, 2013; Suci, 2017;Y. S. Susilo, 2010) berdasarkan catatan Bank Indonesia saat ini penyaluran kredit ke UMKM baru 19,7\% terhadap total penyaluran kredit perbankan nilainya sekitar Rp900 bandingkan dengan Thailand yang sudah mencapai 35\% dan Korea Selatan $40 \%$ begitulah fakta yang terjadi sekarang terkait kredit UMKM sebetulnya pemerintah terus berupaya mendorong pertumbuhan kredit UMKM. Pengembangan terus berjalan mendorong pertumbuhan kredit Indonesia sesuai dengan peraturan nomor 14 yang kemudian dirubah menjadi PB I no. 17 yang isinya bank umum wajib mengalokasikan sebagian kreditnya untuk pengusaha UMKM yang diatur secara bertahap yaitu 5\% pada $201210 \%$ pada $201615 \%$ pada 2017 dan 20\% pada 2018. Bank harus mencari 
nasabah UMKM yang layak lalu sejak 2007 pemerintah juga telah menggulirkan kredit usaha rakyat dengan skema penjaminan kredit kepada bank-bank yang mengeluarkan KUR, dengan skema penjaminan kredit kepada bank- bank yang mengeluarkan kur.Pemerintah membuat program tambahan yakni pemberian dana bergulir atau kredit untuk usaha ultra mikro (Manggabarani et al., 2019; Muttaqin, A. A., \& Hartono, 2019; Surnida, 2020). Program usaha ultra mikro merupakan program dana yang bersifat non bankable. Pemerintah akan memberikan kredit dengan plafon pembiayaan rendah yakni dibawah 10 juta, untuk program ini pemerintah juga telah mengalokasikan dana kredit mikro ultra mikro sebesar 1,5 triliun pada tahun ini pemerintah akan memberikan kredit dengan plafon pembiayaan rendah yakni dibawah 10 juta, untuk program ini pemerintah juga telah mengalokasikan dana kredit ultra mikro sebesar 1,5 triliun pada tahun ini.

Kendala yang ada saat ini baik permasalahan dari sisi UMKM maupun lembaga perbankan (Kara, 2013; Perdagangan, 2013; Suci, 2017), kebanyakan usaha mikro tidak biasa membuat laporan keuangan secara proper hingga mereka hanya mencatat di bon atau catatan buku manual dari pengusaha UMKM tersebut serta menyakinkan diri sendiri untuk layak mendapat kredit Tetapi hanya membuktikannya dengan bon dan catatan buku manual, disisi lain bank harus tetap melakukan asesmen untuk kelayakan kredit. Untuk menjembatani, untuk mengedukasi usaha mikro untuk membuat laporan keuangan yang memenuhi kaidah akuntansi edukasi ini kalau dilatih satu persatu akan makan waktu kemudian dijembatani dengan aplikasi si apik yang bisa diunduh di ponsel pintar berbasis android pengusaha UMKM bisa mengunduh aplikasi tersebut dan membukukan penjualannya dalam aplikasi tersebut.

UMKM menjadi perhatian sendiri dengan pemberian kredit khusus masih terus dilakukan agar membuahkan hasil yang efektif tak sekadar untuk mendorong pertumbuhan bisnis para pengusaha menengah kecil dan mikro akan tetapi lebih daripada itu mengatasi kemiskinan dan ketimpangan kesejahteraan (Indika, M., \& Marliza, 2019; Oktafia, 2017; Prasetyo, 2008), hal ini masih relevan dan jika melihat perkembangan di tanah air, gejolak sosial cenderung ke arah radikalisme dan salah satu penyebabnya adalah ketimpangan sosial di negara kita yang belum bisa diatasi, hal ini dasari ekonomi Indonesia dikuasai $20 \%$ orang terkaya di 
Indonesia maka berkembangnya UMKM diharapkan menjadi solusi ketimpangan sosial ataupun ketimpangan penguasaan ekonomi serta menciptakan banyaknya lapangan kerja untuk masyarakat level bawah.

Agar penyaluran kredit UMKM selaras dengan upaya mengatasi kemiskinan dan ketimpangan sosial pembiayaan ke sektor UMKM harus lebih diarahkan ke sektor produktif seperti industri kecil dan menengah faktanya sekarang hanya 10,5\% kredit UMKM yang mengarah ke sektor manufaktur begitu pula dengan penyaluran kur yang realisasinya mencapai 110 triliun sepanjang 2016 tetapi yang agar penyaluran kredit UMKM selaras dengan upaya mengatasi kemiskinan dan ketimpangan sosial pembiayaan ke sektor UMKM harus lebih diarahkan ke sektor produktif seperti industri kecil dan menengah faktanya sekarang hanya $10,5 \%$ kredit UMKM yang mengarah ke sektor manufaktur begitupula dengan penyaluran kur yang realisasinya mencapai 110 triliun sepanjang 2016 tetapi yang muncul ke sektor produktif non jasa perdagangan hanya 22,60\%.

Memang diperlukan pemetaan yang jelas masalah yang muncul dalam penyaluran pembiayaan untuk UMKM, berdasarkan survei International finance corporation, faktor utama yang menyebabkan pengusaha kecil masih enggan meminjam dari bank adalah terlalu mahal untuk biaya administrasi dan prosedur perbankan yang rumit (Bismala, 2016; Nugroho, L., \& Tamala, 2018), dan bisnis terlalu kecil ini adalah tantangan bagi perbankan untuk mengubah kesan tersebut pengusaha kecil dari enggan berhubungan dengan bank menjadi suka ber bank. Di sisi lain masih dari survei IFC mikro dalam menjalankan usahanya adalah persaingan lokal biaya tinggi ruang usaha kurangnya pembiayaan jaringan bisnis terbatas dan pajak yang tinggi.

Negara Indonesia mendukung berbagai program peningkatan daya saing UMKM yang dilakukan Kadin setidaknya ada empat kendala yang dihadapi UMKM itu masalah pembiayaan teknologi dan inovasi produk riset pasar serta inefisiensi. Permodalan masih menjadi kendala utama karena sulitnya persyaratan untuk mendapatkan kredit perbankan bagi UMKM seperti kelayakan usaha rekening 3 bulan harus bagus keberadaan agunan serta lamanya berbisnis pangan banyak pengusaha UMKM yang sebenarnya bisnisnya sangat feasible namun dirintangi oleh agunan atau lamanya berbisnis. 
Permasalahan teknologi dan inovasi produk problem klasik pengusaha UMKM (Ariani, A., \& Utomo, 2017; Y. Susilo, 2012), dampaknya UMKM Craft kebingungan kita berhadapan dengan ekspansi produk dari pabrik-pabrik yang lebih besar dan mapan makan sulit berkembang dan selamanya jadi pemain medioker alias menengah pada UMKM berhadapan dengan bisnis besar yang sangat peka teknologi dan inovasi 3 lebih efisien dan lebih bisa mengikuti perubahan di pasar.

Kendala berikutnya adalah riset pasar (Anjarsari \& Nandiroh, 2017; Rahayu, 2020), selama ini ada yg terkait model promosi peluang pasar pesaing barang substitusi dan komplementer atas produk-produk pengusaha muda serta konsumen dan pasar serta faktor-faktor eksternal lainnya. Kondisi ini membuat ekspansi bisnis UMKM sangat terbatas tanpa dukungan riset pasar sulit bagi pengusaha pemula untuk bisa mengetahui apa yang kita dibutuhkan di pasar kita butuh pelibatan perguruan tinggi untuk secara intensif melakukan riset pasar soal efisiensi UMKM belum mempunyai tingkat efisiensi yang optimal karena tidak mampu menciptakan skala ekonomi tingkat produktivitas total usaha besar yang padat Capital mencapai 100 kali dibandingkan usaha kecil adapun usaha berskala menengah mempunyai tiga kali dibandingkan usaha kecil, ini menunjukkan betapa UMKM hanya besar dari sisi penyerapan tenaga kerja namun dalam skala dan nilai bisnis mereka kalah jauh dengan perusahaan besar yang padat modal.

Jika ditarik benang merah lemahnya daya saing UMKM memang perlu menjadi perhatian utama untuk dibenahi tidak mampu bersaing ini karena masih rendahnya tingkat kemampuan kewirausahaannya kendala ini tentunya menjadi tugas pemerintah tidak mampu bersaing ini karena masih rendahnya tingkat kemampuan kewirausahaannya kendala ini tentunya menjadi tugas pemerintah dan bank bagaimana meningkatkan kemampuan bersaing mereka (Arifien, 2019; Sedyastuti, 2018).

Dan lembaga perbankan tidak hanya fokus pada bagaimana agar kredit yang tersedia untuk UMKM di saat dia salurkan tapi juga mereka membimbing pendampingan agar mereka terus tumbuh dan naik kelas pengusaha mikro bisa naik travel pulsa kecil pengusaha kecil naik menjadi pengusaha menengah dan pengusaha menengah bisa menjadi korporasi mengenalkan kepada mereka soal teknologi dan proses inovasi membaca trend pasar bagaimana mengelola bisnis 
secara efisiensi merupakan cara untuk meningkatkan kemampuan para pengusaha pelaku bisnis UMKM ini (Kara, 2013; Narsa, I. M., Widodo, A., \& Kurnianto, 2012; Rahmawati, T., \& Puspasari, 2017).

Pemerintah harus berani mengintervensi lembaga penyalur kredit dan bank agar lebih membuka pintu untuk para pelaku usaha mikro bentuk pemerintah siapkan sistem yang dapat membuat pelaku usaha mikro mampu memberikan kredit dengan teratur dan secara bersamaan mengembangkan usaha mereka penanganan cermat dan cerdas agar mereka bisa lebih mudah mendapatkan pembiayaan(Kumorotomo, 2010; Nugroho, L., \& Tamala, 2018; Putra, 2015).

Selain kendala-kendala tersebut di atas terdapat pula faktor penting yang perlu diperhatikan agar penyaluran kredit kecil dan mikro dapat meningkatkan yaitu akses pasar logistik kompetensi pengelolaan keuangan secara sederhana dan agunan (Arumsari, 2019; Hariyanti, 2015), sebagian pengusaha kecil dan mikro di Indonesia belum memiliki akses pasar tepat. Perlu diperhatikan dalam pemberian kredit adalah gunakan saat ini masih banyak petani kecil yang belum memiliki sertifikat tanah pada apabila sertifikat tersebut dapat digunakan sebagai jaminan. Berbagai upaya juga telah dilakukan pemerintah meningkatkan penyaluran kredit bagi pengusaha UMKM tetapi masih mencari pola yang pas dan sesuai dengan kebutuhan usaha UMKM.

Tujuan utama penulisan artikel guna mengetahui model kredit UMKM pada kelompok Bank dan Fintech di Indonesia, melalui kajian studi literatur yang relevan, yaitu dengan mengkaji dan membandingkan hasil wawancara atau interview, muaranya adalah membentuk model atau kebijakan dari hasil atau wawancara tersebut. Metode yang diimplementasikan dalam penelitian ini adalah penelitian kualitatif dimana pendekatan yang dilakukan melalui studi literatur yaitu penelitian yang mengkaji secara kritis pengetahuan, gagasan atau temuan serta memberikan kontribusi teoritis dan metodologis terhadap objek kajian. Data yang digunakan data sekunder dari hasil wawancara yang telah dilakukan. Kebijakan atau model akan terbentuk dari wawancara dari para informan, informan akan menjadi bagian dari validitas data. Umumnya informan adalah sebagai pemutus kebijakan dengan profil mereka adalah pimpinan jabatan puncak di suatu perusahaan tersebut, cukup berpengalaman, mempunyai track record yang baik 
dalam bidang yang ditekuni serta hasil dari kebijakannya sudah dapat dirasakan oleh masyarakat. dimana informannya adalah sebagai berikut (Suryadi et al., 2017): Sis Apik Wijayanto (SAW) direktur consumer BRI, Wawan Setiawan (WS) SVP micro banking group Bank Mandiri, Gunawan Te (GT) SME business head Danamon, Joshephus Koernianto Triprakoso (JKT), Direktur Utama Bank Mandiri Taspen, Pribadi Budiono(PB) Dirut BPR Lestari, Reno Wijaya (RW) Founder modalku, Taufan Garuda Putra (TGP) CEO dan pendiri amartha dan Teguh B. Ari Wibowo (TBAW) direktur pinjaman .co.id.

\section{METODE}

Jenis penelitian yang digunakan adalah pendekatan kualitatif, yaitu penelitian yang digunakan untuk mengetahui makna dari suatu fenomena atau permasalah yang ada dan data bersifat non statistik, riset ini mengarah induktif, dan hasil riset kualitatif lebih memfokuskan makna dibandingkan generalisasi (Sugiyono, 2014). Jenis penelitian termasuk dalam penelitian eksploratif yaitu dilakukan untuk mengetahui dan menjelaskan permasalahan yang awalnya peneliti hanya memahami permasalahan yang ada secara umum, baru kemudian peneliti melakukan riset. Penelitian adalah bagian dari kesinambungan kegiatan ilmiah baik untuk keperluan pengumpulan data, menarika kesimpulan atas gejala-gejala khusus dalam bentuk empirik (Bungin B., 2011). Sampel adalah 10 informan dari pimpinan perusahaan yang saat ini masih beroperasi dan mempunyai integritas dan kredibilitas. Sumber data yang digunakan adalah sumber data sekunder berupa data yang didapatkan secara tidak langsung dari informan atau responden biasanya berupa dalam bentuk data. Metode atau metodologi adalah proses, prinsip, prosedur yang dijalankan untuk mengetahui masalah dan mencari jawaban yang dihipotesiskan. Dengan penjelasan lain, metodologi adalah suatu approach bersifat generalisasi untuk mengulas topik penelitian (Deddy mulyana, 2004). Metode penelitian menggunaan kajian literatur yaitu peneliti mengkaji secara saksama akan literatur yang dibutuhkan dalam riset (Nazir, 2014) dan juga mengkombinasikan dengan menggunakan wawancara pada informan yang diperlukan dalam riset. Metode penelitian yang digunakan adalah studi literatur yang dibutuhkan dalam riset (Nazir, 2014) dan juga mengkombinasikan dengan menggunakan wawancara pada informan yang diperlukan dalam riset. Metode penelitian yang digunakan adalah studi literatur secara sistematis (Espitia et al, 2016). Adapun teknik 
pengumpulan data dijalankan dengan menggunakan data sekunder dengan membandingkan dari wawancara dan data pendukung lainnya, dimana informan adalah pucuk pimpinan dari platform e-commerce digital business. Teknik analisis data kualitatif mengacu pada data model Miles and Huberman, yaitu terdiri dari 3 tahapan antara lain reduksi data, penyajian data dan penarikan kesimpulan

Dalam penelitian kualitatif pendekatan studi literatur ini, peneliti menggunakan tools Nvivo 12, dimana tools ini diakui secara internasional untuk melakukan penelitian kualitatif. dalam Nvivo, sumber data internal (research), sumber data eksternal (external), tulisan tulisan peneliti dalam data collections (memos) dan kerangka (framework matrics). Sumber internal dalam text ini merupakan bagian sumber data penelitian kualitatif yang dapat tampil pada Nvivo 12, misalnya rekaman atau interview record, catatan-catatan dalam melakukan research, picture, table data dalam rurvey research, pengaturan dan termasuk videovideo (Bandur Agustinus, 2016).

\section{HASIL DAN PEMBAHASAN}

\section{Hasil}

Terlampir dibawah matrik mengenai perbandingan informan pada tabel 1 sebagai berikut:

\begin{tabular}{|c|c|c|c|c|}
\hline No & $\begin{array}{c}\text { INFOR } \\
\text { MAN }\end{array}$ & JABATAN & $\begin{array}{l}\text { USA } \\
\text { HA }\end{array}$ & PROGRAM \\
\hline 1 & SAW & $\begin{array}{l}\text { Direktur } \\
\text { Consumer } \\
\text { BRI }\end{array}$ & Bank & $\begin{array}{l}\text { Positif: } \\
\text {-Bantu micro banking bagi BRI adalah } \\
\text { pembiayaan kredit maksimalnya } 200 \text { juta } \\
\text { bisnis microbanking ada umkm } \\
\text {-BRI berhasil penyaluran kredit mikro } \\
\text { sebesar } 653,1 \text { triliun atau naik 16,4\% } \\
\text {-Saat datang mendekati mereka bukan saja ke } \\
\text { pelaku bisnis itu tetapi juga ke komunitas } \\
\text { mereka } \\
\text {-Sangat memperhatikan kearifan lokal dan } \\
\text { kebiasaan lokal setiap daerah sehingga perlu }\end{array}$ \\
\hline
\end{tabular}




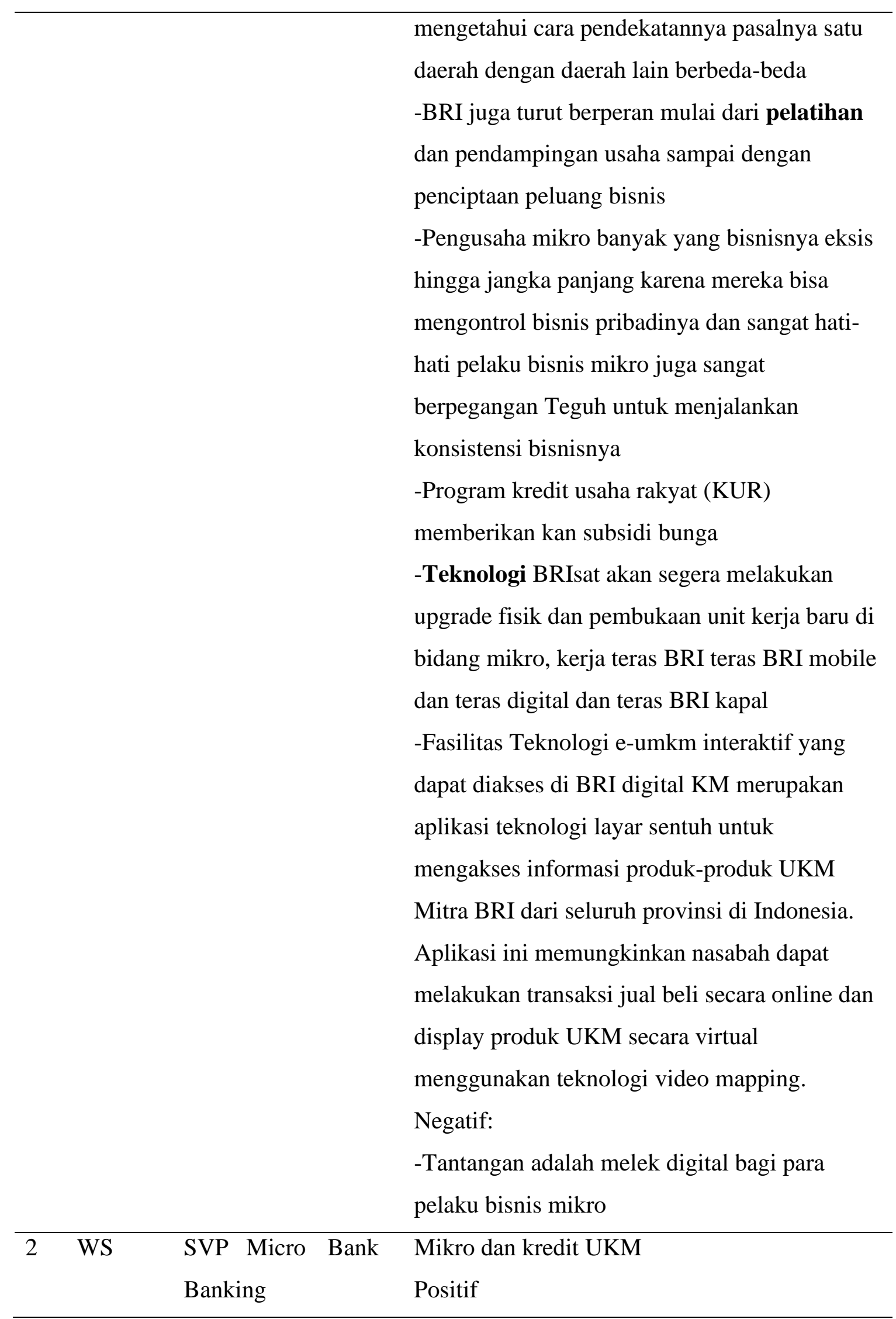




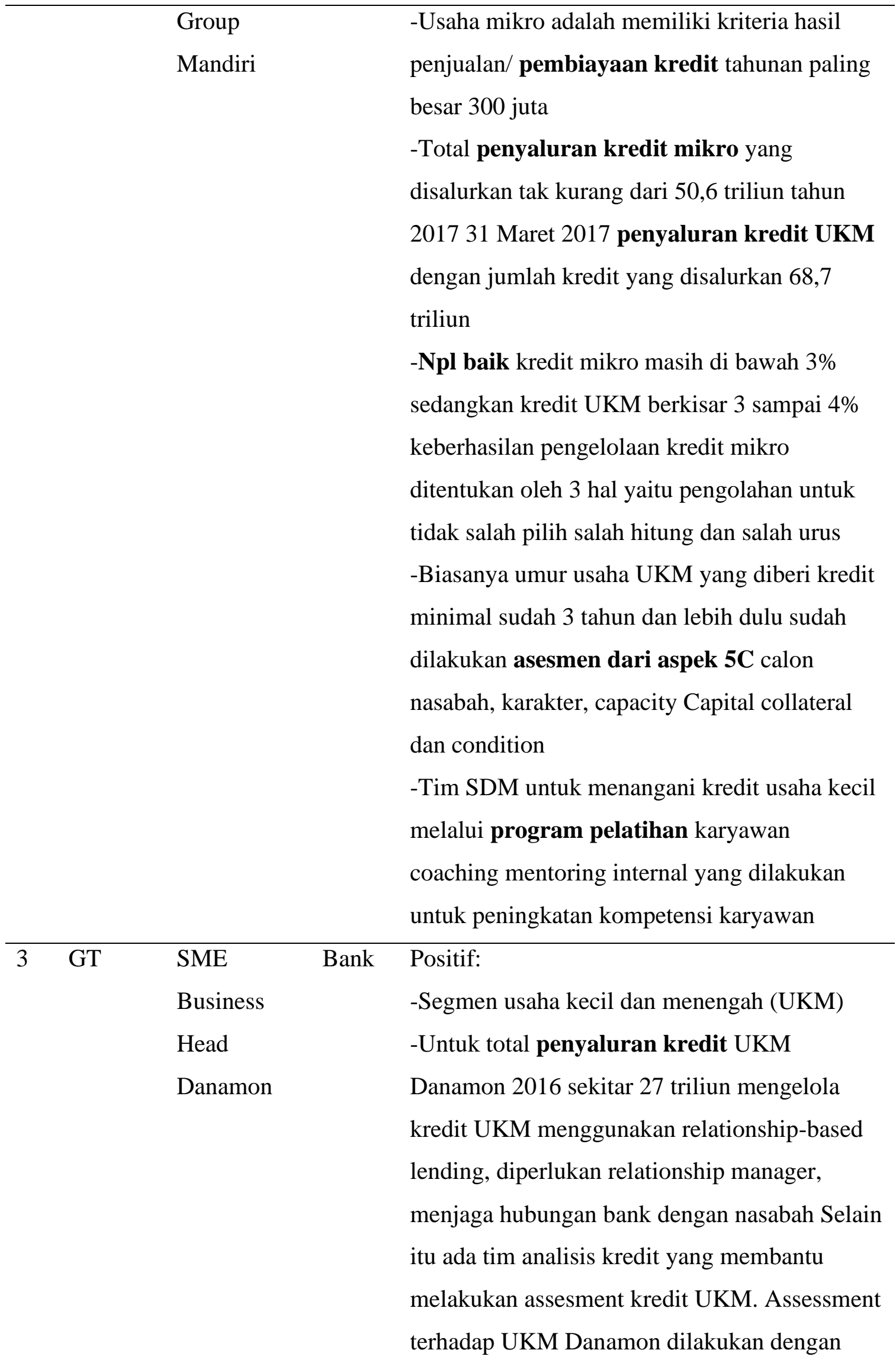




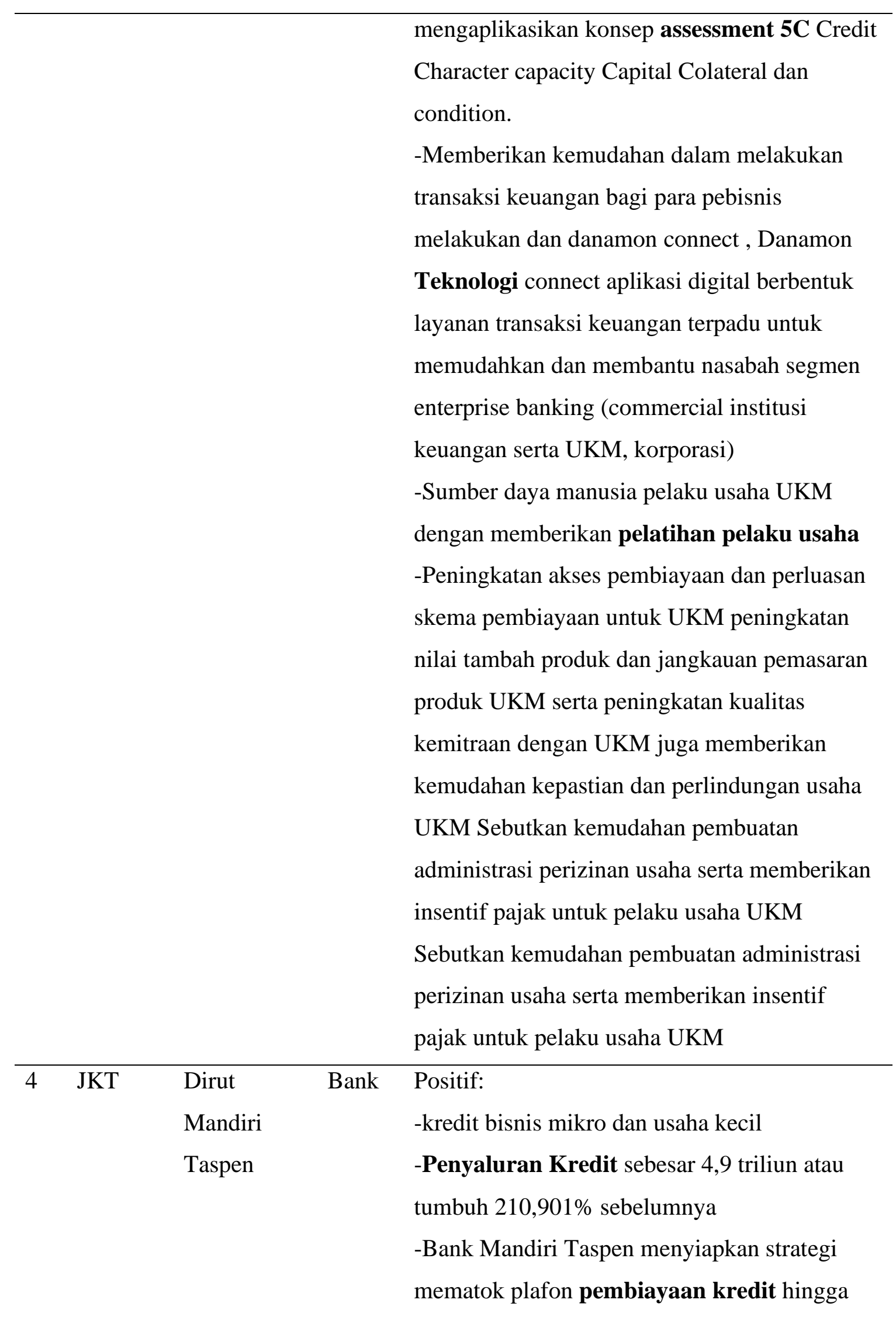


300 juta dengan jangka waktu pinjaman hingga

debitur berusia 75 tahun

-Bank Mandiri Taspen meluncurkan program

sehat dan edukasi perbankan kepada pensiunan

pegawai negeri sipil dan TNI Polri hal itu

bertujuan meningkatkan kesehatan orang lanjut

usia agar tetap aktif dan produktif

-Untuk mengantisipasi kredit macet Bank

Mandiri Taspen menerapkan pendekatan

personal dengan melayangkan surat

pemberitahuan tentang jatuh tempo kredit tiga

hari sebelumnya

-Npl baik di angka 0,9\%

\begin{tabular}{|c|c|c|c|}
\hline $5 \quad \mathrm{~PB}$ & $\begin{array}{l}\text { Dirut BPR } \\
\text { Lestari }\end{array}$ & Bank & $\begin{array}{l}\text { Positif: } \\
\text {-2016 BPR Lestari telah menyalurkan total } \\
\text { penyaluran kredit senilai } 2,3 \text { triliun sebanyak } \\
85 \% \text { memang disalurkan untuk kredit UKM } \\
\text {-Npl baik hanya 1,4\% dan LDR kurang dari } \\
65 \% \text { jaga kualitas kredit BPR Lestari } \\
\text { mempunyai program pendampingan dan } \\
\text { pemantauan yang cukup intensif } \\
\text { Juga membedakan BPR Lestari dari para } \\
\text { pemain besar adalah layanan personalisasi } \\
\text { kepada nasabah setiap nasabah akan berada } \\
\text { dibawah pantauan seorang personal banking } \\
\text { officer yang bertugas melayani dan meretensi } \\
\text { sang nasabah }\end{array}$ \\
\hline $6 \quad \mathrm{RW}$ & $\begin{array}{l}\text { Founder } \\
\text { Modalku }\end{array}$ & $\begin{array}{l}\text { Fintec } \\
\mathrm{h}\end{array}$ & $\begin{array}{l}\text { Positif: } \\
\text {-Kredit macet modal ku sangat rendah hanya } \\
0,05 \% \text { atau nyari } 0 \% \text { npl baik } \\
\text {-Hanya individu yang memiliki karakter yang } \\
\text { baik dan kemampuan membayar saja yang bisa }\end{array}$ \\
\hline
\end{tabular}




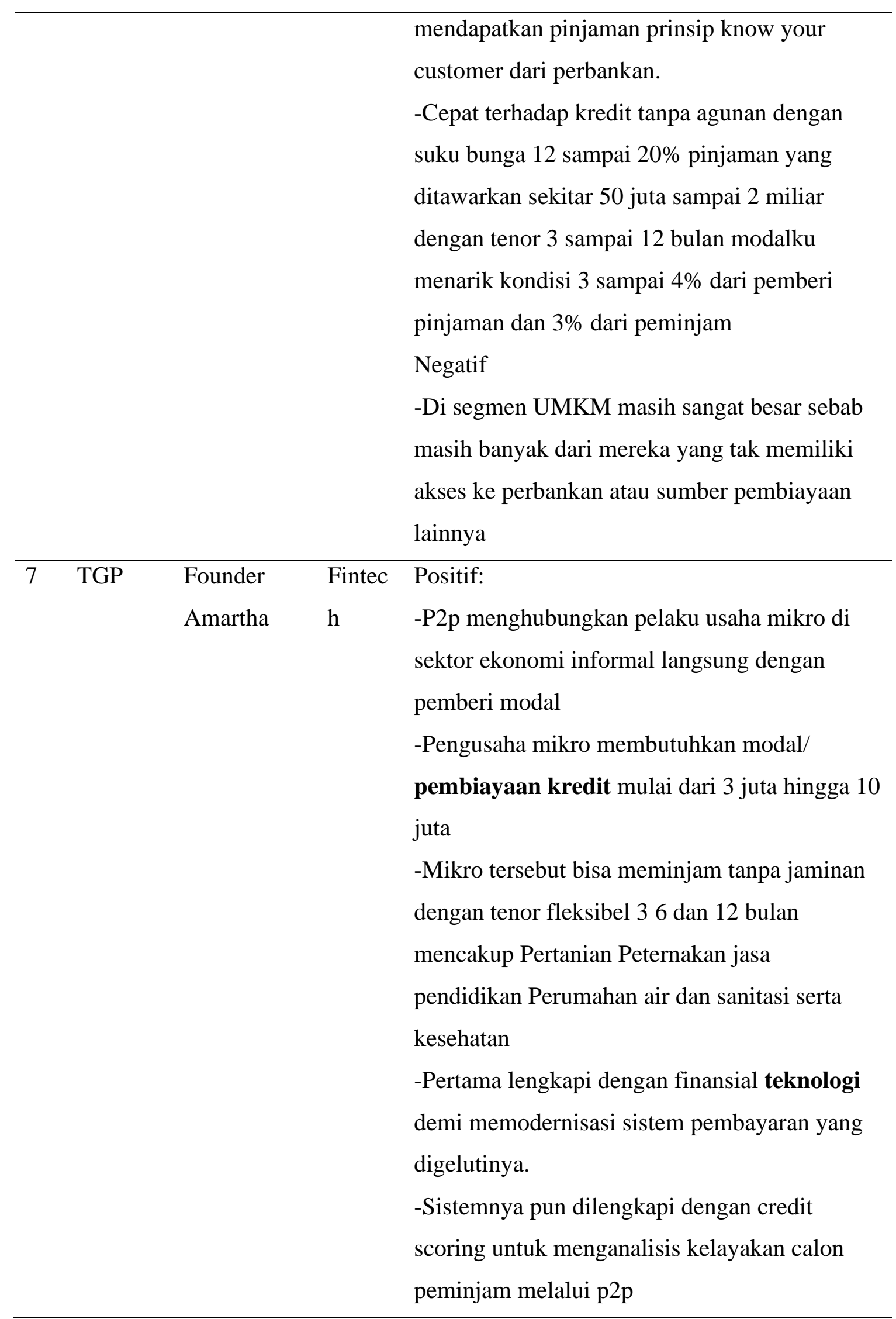


-Mengintegrasikan pendekatan kelompok serta aplikasi online dengan dukungan dari tim lapangan selama jangka waktu pembiayaan -Untuk mendapatkan pembiayaan kredit para calon peminjam diwajibkan membentuk kelompok yang terdiri dari 15 sampai 20 orang di area tempat tinggalnya

-Pelatihan pelaku usaha pun wajib diikuti dari setiap calon peminjam sebelum mereka diberi pembiayaan

-Calon peminjam mengajukan proposal pembiayaan proposal yang telah dikaji tim amartha kemudian didaftarkan di marketplace amartha.com untuk ditawarkan kepada investor yang berminat untuk memastikan kelancaran pembayaran para peminjam selama masa pembayaran setiap mitra usaha wajib menghadiri pertemuan mingguan dengan field officer Amarta yang memonitor perkembangan usaha secara berkala

-Amartha mampu memfasilitasi pinjaman sebesar penyaluran kredit 85 miliar kepada 33000 orang

-Kredit macet nya nihil Iya tapi too good to be true kami and npl baik -nya $0 \%$

-Sebulan Amarta bisa menerima hingga 5 ribu proposal pinjaman dengan nilai 3 sampai 10 juta

Negatif:

-Tangan di Indonesia yang paling berada di bawah piramida masih banyak sekali dan sebagian besar adalah ibu-ibu bidang usahanya 


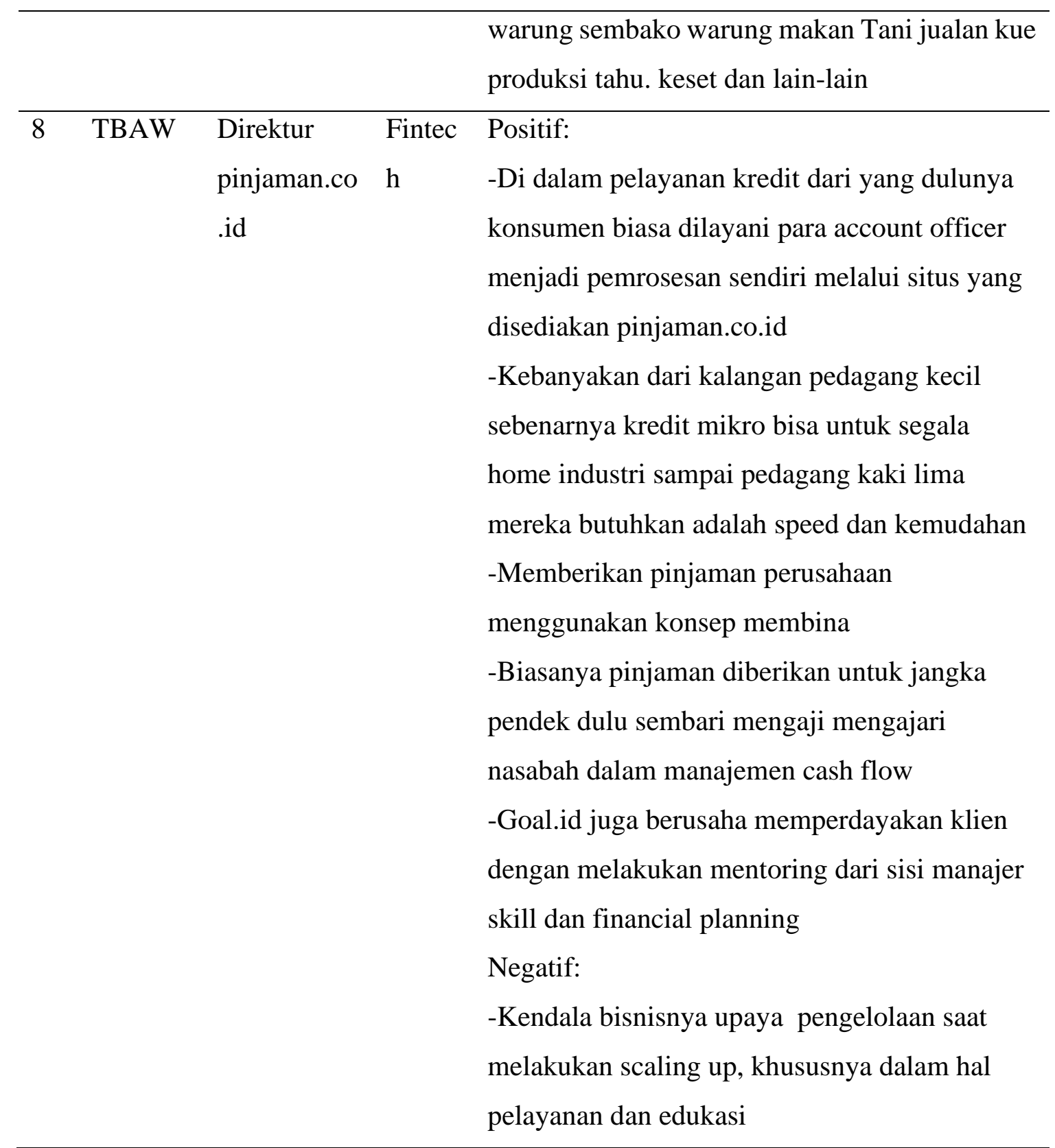

\section{Pembahasan}

Dari hasil diatas, dilakukan uji analisis menggunakan Nvivo 12, untuk mengetahui hasil dari uji yang dilakukan adalah untuk mengetahui kebijakankebijakan yang tepat terhadap UMKM serta model dari kebijakan UMK guna mempermudah untuk mengetahui peta UMKM yang ada saat ini, dimana uji-uji tersebut antara lain:

Dari hasil gambar 1 menunjukkan hubungan yang kuat dari masing masing informan terhadap koding yang telah dilakukan, dimana ditunjukkan dengan garis 
biru, biasanya dinyatakan dengan angka yaitu mendekati angka 1 dan/ atau mutlak 1.

\section{Project Map}

Salah satu fitur yang terdapat di Nvivo 12 untuk menampilkan hasil dari penelitian adalah berbentuk Map. Istilah yang digunakan sebelumnya pada Nvivo 12 adalah model, namun kini sudah diganti dengan istilah Map. Project Map: Map yang bersumber dari coding yang telah dibuat sebelumnya, baik itu files, Nodes, maupun relationships, hal ini mengacu pada tema-tema hasil koding sehingga dapat melihat/ visualisasi hasil koding.

Untuk project Map ini dibagi menjadi 2 dimana yang pertama adalah Map Bank dan Map Fintech.

\section{Map Bank}

Map Bank akan menunjukkan visualisasi hasil dari model yang terbentuk untuk kebijakan bank terhadap usaha kegiatan Mikro, Kecil dan Menengah.

Dari Gambar 3 Map Bank diatas terhadap kebijakan UMKM terdapat 5 Informan dimana membentuk 9 Koding yaitu: Pembiayaan Kredit Bank PBK), Program Bank (PB), Tantangan Perbankan (TP), Pelatihan Pelaku Usaha Bank (PPUB), Teknologi Perbankan (TP), Penyaluran Kredit Bank (PKB), Kebijakan Bank (KB), NPL bank dan Pelatihan Karyawan Bank (PKBK). Hasil ini didukung dari beberapa penelitian sebelumnya menyangkut dari kebijakan diatas (Ardiansyah, 2019; Barus, 2013; Danistyo, 2009; Muzdalifa, Rahma, dan Novalia, 2018; Nisa, 2016; Ratnasari, 2016; Rizal, Maulina dan Kostini, 2019; Sunarsi, 2020).

Dari tabel 2 diatas diatas menunjukkan bahwa informan yang paling terbanyak dalam memberikan kebijakan adalah SAW, kemudian disusul dengan WS dan JKT sebanyak 5 (lima), lalu GT sebanyak 4 (empat) dan terakhir adalah PB dengan jumlah 3 (tiga) yaitu paling sedikit kebijakan yang sama dikeluarkan dengan informan yang lainnya.

\section{Map Fintech}

Map Fintech akan menunjukkan visualisasi hasil dari model yang terbentuk untuk kebijakan fintech terhadap usaha kegiatan Mikro, Kecil dan Menengah. 
Dari Gambar 4 Map Fintech diatas terhadap kebijakan UMKM terdapat 7 kebijakan dimana antara lain adalah: Kebijakan Fintech (KF), NPL Fintech (NPLF), Pelatihan Pelaku Usaha Fintech (PPUF), Pembiayaan Kredit Fintech (PKF), Penyaluran Kredit Fintech (PSKF), Tantangan Fintech (TF), Teknologi Fintech (TEF). Hasil ini didukung dari beberapa penelitian sebelumnya menyangkut dari kebijakan diatas (Ardiansyah, 2019; Barus, 2013; Danistyo, 2009; Muzdalifa, Rahma, dan Novalia, 2018; Nisa, 2016; Ratnasari, 2016; Rizal, Maulina dan Kostini, 2019; Sunarsi, 2020).

Dari tabel 3 diatas menunjukkan bahwa informan yang paling terbanyak dalam memberikan kebijakan adalah TGP dimana terbanyak 7 (tujuh) dari 7 (tujuh) yang tersedia, kemudian diikuti oleh RW sebanyak 3 (tiga) dan terakhir adalah TBAW sebanyak 2 (dua).

\section{SIMPULAN}

Dari hasil penelitian dapat disimpulkan bahwa penerapan model atau pola Validitas data sudah ditunjukkan dengan 8 nforman yang merupakan pimpinan dari suatu perusahaan dimana kebijakan yang dilakukan telah di jalankan sehingga perusahaan tersebut tercapai goal yang telah ditentukan di perkuat dengan pengalaman yang telah dilakukan dibidangnya masing-masing informan berikut dengan kompetensi yang mereka miliki.

Analisis klaster yang dilakukan secara serempak baik untuk bank dan fintech telah menunjukkan hubungan yang kuat antara kata-kata dalam hasil koding yang dilakukan, dimana koding tersebut ada 18 koding yang telah dilakukan, semua koding menunjukkan hubungan yang kuat.

Project Map baik untuk bank dan Fintech adalah sebagai berikut, Bahwa Map pada bank dari 5 informan, membentuk kesamaan model atau map untuk kebijakan yang serupa yaitu PKB (Penyaluran Kredit Bank) dan KB (Kebijakan Bank), artinya semua informan setuju dalam membentuk model atau map menyangkut kebijakan UMKM bahwa bank harus memperhatikan PKB (Penyaluran Kredit Bank) yang maksimal sehingga pelaku atau wirausahawan UMKM dapat secara maksimal untuk melakukan kegiatan usahanya dan hal ini tentu berkorelasi dengan KB (Kebijakan Bank) yang mana harus flexibel, ramah dan kontrol terhadap pelaku atau wirausahawan UMKM. 
Kebijakan lainnya yaitu ada 3 (tiga) yang serupa dengan informan lainnya yaitu PBK (Pembiayaan Kredit Bank) dan NPL (Non Performing Loan), kebijakan ini juga sangat mempengaruhi hubungan bank dengan pelaku UMKM dalam meningkatkan kegiatan usaha dan menjaga hubungan yang terus signifikan.

Project Fintech, 3 informan pada Fintech, hanya 1 informan yang mendominasi keputusan dalam kebijakan yang menyangkut pelaku atau wirausahawan UMKM yaitu KF (Kebijakan Fintech), NPLF (NPL Fintech), PPUF (Pelatihan Pelaku Usaha Fintech), PKF (Pembiayaan Kredit Fintech) Penyaluran Kredit Fintech (PSKF), Tantangan Fintech (TF), Teknologi Fintech (TEF) sedangkan yang lainnya hanya 3 (tiga) dan 2 (dua), namun itu semua dari 3 informan yang mempunyai kesamaan dalam kebijakan yaitu pada $\mathrm{KF}(\mathrm{Kebijakan}$ Fintech) dan tantangan Fintech (TF) ini menunjukkan bahwa perkembangan fintech dipengaruhi dengan kebijakan yang meringankan dan mempermudah pelaku atau wirausahawan UMKM dalam melakukan kegiatannya namun disisi lain pada fintech masih ada hambatan yang ditunjukkan dengan Tantangan Fintech (TF) yaitu Di segmen UMKM masih sangat besar sebab masih banyak dari mereka yang tak memiliki akses ke perbankan atau sumber pembiayaan lainnya, beserta pelayanan dan edukasi.

Saran untuk penelitian selanjutnya adalah memperbesar jumlah sampel dan melakukan analisis lebih dalam dan detail pada masing-masing koding yang dilakukan baik itu analisis untuk informan maupun data yang dikembangkan, pada informan data lebih diolah menjadi lebih detail lagi sehingga korelasi antara dengan informan terhadap data yang diuji mendapatkan sesuatu makna yang baru hingga memberikan masukan atau keputusan akan lebih tepat dan mempunyai implikasi yang baik terhadap kegiatan perusahaan nanti.

\section{DAFTAR RUJUKAN}

Adibah, F. (2018). Peningkatan Daya Saing UMKM Kabupaten Pasuruan untuk menopang Perekonomian Nasional dalam menghadapi persaingan global. MAGISTRA: Jurnal Ilmu Manajemen, 2(2), 85-92.

Anggraeni, F. D. (2013). (2013). Pengembangan Usaha Mikro, Kecil dan Menengah (UMKM) Melalui Fasilitasi Pihak Eksternal dan Potensi Internal 
(Studi Kasus Pada Kelompok Usaha" Emping Jagung" di Kelurahan Pandanwangi Kecamatan Blimbing Kota Malang). Jurnal Administrasi Publik, 1(6), 1286-1295.

Anjarsari, N. P., \& Nandiroh, S. (2017). Riset Pasar Produk Piemirsa (Pie Intip

Rasa-rasa). (Doctoral dissertation, Universitas Muhammadiyah Surakarta).

Ardiansyah, T. (2019). Model financial dan teknologi (fintech) membantu permasalahan modal wirausaha UMKM Di Indonesia. Majalah Ilmiah Bijak, $16(2), 158-166$.

Ariani, A., \& Utomo, M. N. (2017). Kajian Strategi Pengembangan Usaha Mikro Kecil dan Menengah (UMKM) di Kota Tarakan. Jurnal Organisasi Dan Manajemen, 13(2), 99-118.

Arifien, S. R. (2019). Analisis Strategi Pemasaran Untuk Meningkatkan Daya Saing UMKM. Konferensi Nasional Ilmu Administrasi, 3(1).

Arumsari, D. T. (2019). Pengaruh Literasi Keuangan Dan Kompetensi Sdm Terhadap Kinerja Ukm Di Jawa Timur. (Doctoral dissertation, STIE Perbanas Surabaya).

Bandur Agustinus. (2016). Penelitian kualitatif Metodologi, Desain dan Teknik Analisis Data dengan Nvivo 11 plus. (Jatmiko, Ed.) (Pertama). jakarta: Mitra Wacana Media.

Barus, A. C. (2013). Pengaruh spread tingkat suku bunga dan rasio keuangan terhadap penyaluran kredit UMKM pada bank umum di Indonesia. Jurnal Wira Ekonomi Mikroskil: JWEM, 3(1), 11-20.

Bismala, L. (2016). Model Manajemen Usaha Mikro Kecil dan Menengah (UMKM) untuk Meningkatkan Efektivitas Usaha Kecil Menengah. Jurnal Entrepreneur Dan Entrepreneurship, 5(1), 19-26.

Budhi, M. K. S. (2018). Efektivitas Penyaluran Kredit Usaha Rakyat PT. BRI (Persero) Unit Blahkiuh Terhadap Produktivitas UKM dan Pendapatan UKM Penerima KUR di Kecamatan Abiansemal. E-Jurnal Ekonomi Dan Bisnis Universitas Udayana, 959-986. 
Budiarto, R., Putero, S. H., Suyatna, H., Astuti, P., Saptoadi, H., Ridwan, M. M., \& Susilo, B. (2018). Pengembangan UMKM Antara Konseptual dan Pengalaman Praktis. UGM PRESS.

Bungin B. (2011). Metodologi Penelitian Kualitatif. jakarta: rajawali pers.

Danistyo, G. (2009). Analisis faktor-faktor yang mempengaruhi permintaan dan penawaran kredit UMKM di Indonesia.

Deddy mulyana. (2004). Metodologi Penelitian Kualitatif (Paradigma Baru Ilmu Komunikasi Dan Imu Sosial lainnya). Bandung: PT Remaja Rosmadakarya,.

Espitia et al. (2016). Systematic Literature Review of the Implementation of Knowledge Codification Process. In European Conference Knowledge Management (p. 1111). Passau: Academic Conferences International Limited.

Hariyanti, A. I. (2015). Peningkatan keterampilan manajemen keuangan yang berdampak pada ketersediaan sistem akuntansi formal Usaha Mikro Kecil dan Memengah (umkm) di kabupaten brebes. Sustainable Competitive Advantage (SCA), 5(1).

Hasanah, N., \& Priantina, Y. (2017). Pengaruh Tingkat Suku Bunga, Inflasi dan Rasio Kecukupan Modal terhadap Penyaluran Kredit UMKM oleh Bank Umum di Indonesia Tahun 2007-2013. Jurnal Informasi Akuntansi Dan Keuangan (INFAK), 3(2), 106-113.

Indika, M., \& Marliza, Y. (2019). Upaya Upaya Pemberdayaan Usaha Mikro Kecil Menengah (UMKM) Dalam Mengatasi Kemiskinan di Kecamatan Tugumulyo Kabupaten Musi Rawas. Journal Management, Business, and Accounting, 18(3), 49-66.

Irwan, I. (2020). Tinjauan Yuridis penyaluran Kredit Usaha Rakyat (KUR) bagi pelaku Usaha Mikro Kecil dan Menengah (UMKM)(Studi di Bank Rakyat Indonesia Cabang Labuan Bajo). (Doctoral dissertation, UNIVERSITAS MUHAMMADIYAH MATARAM).

Kara, M. (2013). Konstribusi Pembiayaan Perbankan Syariah Terhadap Pengembangan Usaha Mikro Kecil Dan Menengah (UMKM) Di Kota Makasar. Asy-Syir'ah: Jurnal Ilmu Syari'ah Dan Hukum, 47(1). 
Kumorotomo, W. (2010). Perubahan Paradigma Peran Pemerintah dalam Pemberdayaan Koperasi dan UMKM.

Manggabarani, A. S., Marzuki, F., \& Triwahyuningtyas, N. (2019). Percepatan pengurangan kemiskinan melalui workshop program pembiayaan ultra mikro dan permodalan nasional madani bagi UMKM di desa margamulya. SABDAMAS, 1(1), 106-110.

Muttaqin, A. A., \& Hartono, A. R. (2019). Implementasi Penerapan Pembiayaan Ultra Mikro di BMT-UGT Sidogiri. El-Barka: Journal of Islamic Economics and Business, 2(2), 273-299.

Muzdalifa, I., Rahma, I. A., \& Novalia, B. G. (2018). Peran fintech dalam meningkatkan keuangan inklusif pada UMKM di Indonesia (pendekatan keuangan syariah). Jurnal Masharif Al-Syariah: Jurnal Ekonomi Dan Perbankan Syariah, 3(1).

Narsa, I. M., Widodo, A., \& Kurnianto, S. (2012). Mengungkap kesiapan UMKM dalam implementasi standar akuntansi keuangan entitas tanpa akuntabilitas publik (PSAK-ETAP) untuk meningkatkan akses modal perbankan. Jurnal Ekonomi Dan Bisnis Airlangga (JEBA)| Journal of Economics and Business Airlangga, 22, 3 .

Nazir. (2014). Metode Penelitian. jakarta: Ghalia Indonesia.

Nisa, C. (2016). Analisis Dampak Kebijakan Penyaluran Kredit Kepada Umkm Terhadap Pertumbuhan Pembiayaan Umkm Oleh Perbankan [Policy Impact Analysis of Lending to MSMEs on the Growth of MSMEs Financed by Banks]. DeReMa (Development Research of Management): Jurnal Manajemen, 11(2), 212-234.

Nugroho, L., \& Tamala, D. (2018). Persepsi Pengusaha UMKM Terhadap Peran Bank Syariah. Jurnal SIKAP (Sistem Informasi, Keuangan, Auditing Dan Perpajakan), 3(1), 49-62.

Oktafia, R. (2017). Percepatan Pertumbuhan Usaha Mikro, Kecil Dan Menengah (Umkm) Melalui Perkuatan Lembaga Keuangan Mikro Syariah (Lkms) Di Jawa Timur. In In Proceedings of Annual Conference for Muslim Scholars (No. Seri 1, pp. 85-92). 
166 | Jurnal Pendidikan dan Kewirausahaan Vol. 9 No. 12021

Perdagangan, K. (2013). Analisis Peran Lembaga Pembiayaan Dalam Pengembangan UMKM. jakarta: Pusat Kebijakan Perdagangan Dalam Negeri.

Prasetyo, P. E. (2008). Peran usaha mikro kecil dan menengah (umkm) dalam kebijakan penanggulangan kemiskinan dan pengangguran. Akmenika Upy, $2(1), 1-13$.

Putra, T. G. (2015). Peran pemerintah daerah dan partisipasi pelaku usaha dalam pengembangan UMKM manik-manik kaca di Kabupaten Jombang. Jurnal Kebijakan Dan Manajemen Publik, 3(1).

Rahayu, S. N. (2020). Strategi Pemasaran UMKM Rumah Makan (Studi di Desa Qurnia Mataram Seputih Mataram Lampung Tengah). (Doctoral dissertation, IAIN Metro).

Rahmawati, T., \& Puspasari, O. R. (2017). Implementasi sak etap dan kualitas laporan keuangan umkm terkait akses modal perbankan. Jurnal Kajian Akuntansi, 1(1)

Ratnasari, N. (2016). Variabel-Variabel Yang Mempengaruhi Penyaluran Kredit Kepada Umkm Oleh Perbankan Di Indonesia Tahun 2011-2015. Jurnal Pendidikan Ekonomi (JUPE), 4(3).

Rifa'i, A. (2010). Peran UMKM dalam pembangunan daerah: fakta di Provinsi Lampung. Jurnal Ilmiah Administrasi Publik Dan Pembangunan ADMINISTRATIO, 1(2), 133-143.

Rizal, M., Maulina, E., \& Kostini, N. (2019). Fintech sebagai salah satu solusi pembiayaan bagi UMKM. AdBispreneur: Jurnal Pemikiran Dan Penelitian Administrasi Bisnis Dan Kewirausahaan, 3(2), 89-100.

Sedyastuti, K. (2018). Analisis Pemberdayaan UMKM dan Peningkatan Daya Saing Dalam Kancah Pasar Global. ..NOBIS: Jurnal Inovasi Bisnis Dan Manajemen Indonesia, 2(1), 117-127.

Suci, Y. R. (2017). Perkembangan UMKM (Usaha mikro kecil dan menengah) di Indonesia. Cano Ekonomos, 6(1), 51-58.

Sudaryanto, R., \& Wijayanti, R. R. (2013). S. pemberdayaan U. menghadapi pasar bebas A. (2013). Strategi pemberdayaan UMKM menghadapi pasar bebas 
167 | Jurnal Pendidikan dan Kewirausahaan Vol. 9 No. 12021

Asean. Pusat Kebijakan Ekonomi Makro. Badan Kebijakan Fiskal. Kementerian Keuangan, Jakarta.

Sudjinan, S., \& Juwari, J. (2018). (2018). Pemberdayaan Potensi Masyarakat Melalui Pendampingan UMKM Dan Koperasi Di Kelurahan Telaga Sari

Kota Balikpapan. Jurnal Abdi Masyarakat Ilmu Ekonomi (JAMIE), 1(01), $40-49$.

Sugiyono, P. D. (2014). Memahami penelitian kualitatif. bandung: alfabeta.

Sunarsi, D. (2020). Implikasi Digitalisasi Umkm. Digitalisasi UMKM, 57.

Surnida, D. (2020). Pembiayaan Ultra Mikro Dalam Peraturan Menteri Keuangan No 95/PMK. 05/2018 dan Fatwa Dewan Syariah Nasional No 119/DSNMUI/II/2018. MUAMALATUNA, 12(1), 100-123.

Suryadi, D., Banirestu, H., Sudarmadi, Diahnisa, T., Anggoro, A., Silawati, ... Djatmiko, harmanto edy. (2017). Raja raja kredit mikro, kecil dan menengah. Swa.

Susilo, Y. (2012). Strategi meningkatkan daya saing umkm dalam menghadapi implementasi cafta dan mea. Buletin Ekonomi.

Susilo, Y. S. (2010). Peran perbankan dalam pembiayaan UMKM di provinsi DIY. Jurnal Keuangan Dan Perbankan, 14(3), 467-478. 